\title{
EL ANUNCIO DE PERMUTA: NACIMIENTO Y DESARROLLO DE UNA TRADICIÓN DISCURSIVA
}

\author{
PERMANENT HOUSING SWAP ANNOUNCEMENT: DISCURSIVE TRADITION \\ ORIGIN AND DEVELOPMENT
}

\author{
Marlen A. DOMÍNGUEZ HeRNÁNDEZ \\ Loisi SAÍNZ PADRÓN \\ Universidad de La Habana
}

\section{RESUMEN:}

En este artículo se presenta el anuncio de permutas en Cuba, en su surgimiento como una tradición discursiva que evoluciona desde la inmediatez hacia la distancia. Dado un marco escénico de dos personas con necesidades complementarias de cambio de casa, se analiza la estructura de este discurso, y los recursos con que se logra la seducción o la persuasión. También se estudia la imagen tanto del enunciador como del enunciatario, que se colige del texto. Se evidencia que en este producto comunicativo para el consumo cultural, el mensaje esencial no se refiere a las características del producto transaccional, sino a la voluntad suasoria, y al acto directivo incluido. En la voluntad de crear expectativas y suscitar actitudes, se reproducen creencias y valores; las selecciones léxicas, sintácticas y estructurales muestran y perpetúan el imaginario social que de este dominio tienen los hablantes, de modo que se ofrecen datos para el vínculo entre la historia lingüística externa e interna en Cuba.

PALABRAS CLAVE: tradición discursiva, pragmalingüística, acto directivo, género publicitario, anuncios clasificados, imaginario social.

\section{ABSTRACT:}

This paper shows the permanent housing swap (permuta) announcement in Cuba, its emergence as a discoursive tradition evolving from the closer, friendly language to a distant one.We analyse the discourse structure and seduction or persuasion resources, when people with permanent housing swap complementary needs berelated.

We also study the image of the sender and recipient, inferred from the text. Commonly, in this cultural consumer product, the research proves that the essential message is not about transactional product characteristics, but suasive intention and directive act involved. The sender creates expectations and promotes attitudes, and so he reproduces beliefs and values: lexical, syntactic and structural selections show and perpetuate the social imaginary of this domain, and therefore they provide data for linking external and internal linguistic history in Cuba.

KEY WORDS: discoursive tradition, pragmalinguistics, directive act, publicity genre, announcement, social imaginary. 


\section{INTRODUCCIÓN}

A partir de las ideas de Coseriu (1981) acerca de la existencia de técnicas históricamente determinadas en virtud de las cuales se pone en uso el lenguaje, otros autores, como Oesterreicher $(2001,2004)$ analizan fenómenos de la realidad lingüística y desarrollan conceptos tales como concepcionalidad y tradición discursiva.

La concepcionalidad - entendida como la forma que adopta un enunciado según la situación comunicativa (Oesterreicher, 2004: 733 y ss.)- se mueve entre los extremos de la inmediatez y la distancia comunicativas. Por su parte, las tradiciones discursivas son modelos históricos para la producción y recepción discursivas (Oesterreicher, 2001: 200), cuya índole favorece «la creación, fijación y expansión de nuevas formas discursivas» (id.: 207), así como la obsolescencia y pérdida de otras.

En el caso que nos ocupa, trataremos de presentar el proceso de nacimiento y desarrollo de una tradición discursiva que parte de la inmediatez y va, paulatinamente, adquiriendo características propias de la distancia, con las restricciones que ello supone. Perteneciente a los géneros ${ }^{1}$ publicitarios (Cassany, 2004: 919 y ss.), el anuncio de permutas en su evolución se ha conformado como un discurso mixto: con la impronta de la oralidad, ha llegado a ser dispuesto, con diferentes niveles de formalización, para el medio escrito, para la oralidad elaborada y para el entorno web. La finalidad comunicativa de este discurso puede ser la «seducción»o la persuasión y allí se ve a todo interlocutor como un potencial «permutante», dado que el marco escénico son dos personas con necesidades complementarias de cambio de casa ${ }^{2}$. La estructura con que ello se logra, los recursos y la imagen que se ofrece tanto del locutor como del interlocutor se analizarán en el curso del trabajo.

Condicionado históricamente, el fenómeno de los cambios de casas -y los anuncios que se crean para promoverlos-, se refleja en la variedad cubana del español, y la «institucionalización» de sus recursos léxico-semánticos se observa si se revisa hoy el estado final del Diccionario de americanismos (DA), donde se encuentran, referidas con marca de cubanismo, las siguientes acepciones del verbo permutar:

1. intr. $C u$. Intercambiar alguien su casa por otra mediante un trámite legal. En Cuba este verbo se emplea solamente para el intercambio de casas y puede construirse con un complemento de régimen encabezado por la preposición con.

${ }^{1}$ Con Cassany, «denominamos género al grupo de textos que comparten unos mismos parámetros contextuales (propósito comunicativo, rol y estatus del emisor y del receptor, tipo de interacción, ámbito social, etc.) reconocidos socialmente y unos mismos recursos y estructuras lingüísticas», p. 921 (la negrita es nuestra).

${ }^{2}$ Para estos conceptos véase Herrero Cecilia (2006: 166 y ss.).

NORMAS. REVISTA DE ESTUDIOS LINGÜÍSTICOS HISPÁNICOS, NÚMERO 1 (AÑO 2011):

http//www.uv.es/normas

(ISSN 2174-7245) 
2. tr. $\mathrm{Cu}$. Intercambiar alguien su casa por otra mediante un trámite legal. En Cuba este verbo se emplea solamente para el intercambio de casas y puede construirse con un complemento de régimen encabezado por la preposición con.

Ellas nos muestran el uso tanto transitivo como intransitivo del verbo, que ha sufrido un proceso de especialización semántica. Se echa de menos, sin embargo, en la misma obra, la presencia del sustantivo permuta, que viene a completar el campo en que aquellas lexías se inscriben.

En la historia cubana reciente, en el plano legal, el proceso se inicia a partir de la Ley de Reforma Urbana promulgada en 1960, en la cual se establece que: «Los inmuebles que resulten transmitidos en virtud de las disposiciones de la presente Ley, no podrán ser permutados...» (Artículo 29 de la Ley de Reforma Urbana, 14 de octubre de 1960). En este texto aparece el verbo en una estructura de pasiva, con valor transitivo y muy cercano a su acepción regular del diccionario general de la lengua española, referido al argumento «inmueble» 0 «vivienda».

En la medida en que se suceden modificaciones se va produciendo la especificación de sentido: «Las viviendas podrán ser permutadas libremente por sus propietarios...»; «La permuta a que se refieren los artículos precedentes se formalizará por escritura ante notario público» (Ley General de la Vivienda, 27 de diciembre de 1984); lo cual se refleja en la estructura gramatical con la aparición del sustantivo permuta, sin modificadores: «el usufructo de la vivienda que ocupan por permuta» (id. al anterior); «El Instituto Nacional de la Vivienda instruirá el procedimiento y las reglas para la permuta» (Artículo 52 de la Ley No. 65, Ley General de la Vivienda, 23 de diciembre de 1988); y la aparición de derivados sustantivos como permutantes: «En los casos en que se trate de uno o más permutantes que concurran como usufructuarios onerosos, la dirección municipal de la vivienda consignará...»».

Al revisar el documento que integra todas las regulaciones y disposiciones al respecto (Ley No. 211, 19 de julio de 2000, que modifica los artículos 15 y 69 y la Disposición Especial Séptima de la Ley 65), se advierte ya el sustantivo pluralizado: «El presente reglamento tiene como objetivo regular el procedimiento para la autorización de las permutas de viviendas, habitaciones y accesorias...»; mientras que en el Reglamento de permutas, de 2003, que implementa la aplicación de la Ley, se observa que se ha extendido la intransitivización del verbo: «El arrendatario de una vivienda propiedad del Estado, al permutar, mantendrá su misma condición legal»; «Los usufructuarios de habitaciones o accesorias, al permutar entre sí mantendrán igual concepto legal de ocupación»; «Si en el término de contestación, el propietario o conviviente que se pretende obligar a permutar alega que..»; «que el copropietario que resulte obligado a permutar no se afecte económicamente»; lo que significa la maduración del proceso de restricción sémica del verbo.

Lo jurídico es expresión del curso de la vida: con el tiempo, las personas que habían sido beneficiadas por la Ley de Reforma Urbana de 1960 necesitaban otras 
condiciones de vivienda y comenzaron a acudir a cierto lugar de la ciudad -en el caso de los habaneros un punto del Paseo del Prado- para reunirse y expresar sus necesidades ${ }^{3}$, primero verbalmente y luego en carteles artesanales, que fueron surgiendo, y que cada uno elaboraba a su manera. Allí el inicio del intercambio transaccional partía de la pregunta: ¿Qué tú (usted) tienes (tiene)?, o una semejante, y si al locutor le era conveniente lo que se le ofrecía, continuaba con una pregunta del tipo: ¿Qué quiere(s)?

En el surgimiento mismo del tipo - de lo cual es evidencia la propia elaboración del texto- se presenta un problema: cómo hacer atractivo y deseable un «producto» que el promovente no quiere conservar para sí mismo.

Los primeros anuncios de permuta con un carácter más estable comenzaron a aparecer en las paradas de los ómnibus y otros sitios de gran concurrencia de personas, y también en las puertas de las casas objeto de trueque. Para este momento, lo característico era la variabilidad, aunque el soporte papel comienza a dar lugar a ciertas regularidades, como la presencia del verbo permutar, bien en la tercera persona del singular con valor indeterminado por el encubrimiento del actante1 (Se permuta), o conjugado en la primera persona del singular con mayor atención a su carácter agentivo al valerse de la flexión (Permuto). Tipográficamente esta parte del texto se va estabilizando en un puntaje de letra mayor que el resto del mensaje si lo hay. Además se podía aludir a las condiciones de la vivienda ofrecida o requerida, pero mayormente se indicaba un teléfono o dirección de contacto y un nombre de persona, generalmente de mujer y sin apellido. Según la clasificación de Ramírez Caro (2001), esta conformación se relacionaría con el anuncio publicitario cerrado, en que solo aparece un proponente y un «producto», en este caso implícito en el contenido semántico y la relación sintáctica del verbo, pero no se apela al destinatario, ni se emplean imperativos para conminarlo.

\section{REGULARIZACIÓN EN EL MEDIO ESCRITO. LA REVISTA OPINA}

En 1979 surge una revista de corta duración, Opina, que desempeñó un papel muy importante en cuanto a la estabilización del anuncio de permuta, y en su traslado de la concepcionalidad de la cercanía a la de la distancia comunicativa. Ello fue así porque Opina incluyó una sección de clasificados, desaparecida de la prensa del período

3 Más tarde, incluso, surge un oficio no reconocido legalmente, el del «corredor de permuta(s)», también llamado peyorativamente «permutero»-, personaje que se dedica a hacer las gestiones de intercambio de viviendas a cambio de un pago, establecido a priori, o al cabo del término exitoso de su gestión.

NORMAS. REVISTA DE ESTUDIOS LINGÜÍSTICOS HISPÁNICOS, NÚMERO 1 (AÑO 2011):

http//www.uv.es/normas

(ISSN 2174-7245) 
revolucionario previo, en la que se consignaban intenciones de venta, compra e intercambio, entre estos últimos el de vivienda.

Los anuncios que allí se conforman presuponen expectativas personales, elementos afectivos y toman en cuenta el universo de referencias del receptor posible ${ }^{4}$, lo cual en ocasiones lleva al locutor a cierta ocultación de información. Ello forma parte, sin embargo, a juicio de Núñez y Del Teso del «convenio tácito» de no veracidad o incompletitud que rige este tipo de intercambio comunicativo (Núñez y Del Teso: 180).

A partir del surgimiento del clasificado de Opina referido a la permuta, se estabiliza entonces la estructura, del siguiente modo:

Dentro de un acápite rubricado $1 x 1,1 \times 2$ o $2 x 1$, que hacía referencia al número de inmuebles que se ofrecían (primera cifra) y se necesitaban (segunda cifra), se relacionaban los anuncios individuales de permuta. Esta cláusula, a la que llamaremos de entrada, semejante al eslógan publicitario en cuanto a su brevedad, atractivo y vínculo con el resto del texto, no coincide, sin embargo, con aquel, al no presentar ambigüedad semántica, una vez que se ha contextualizado en la cultura esta convención.

La cláusula de entrada del anuncio de permutas, enunciado nuevo, con claves de abreviación y restricción semántica, se estabilizará rápidamente, bien como encabezamiento de secciones o de anuncios individuales, y será eficaz en la medida en que propone la temática y orienta claramente la recepción del anuncio.

El peso de la intención comunicativa (hacer creer $\rightarrow$ hacer hacer según Charadeau) (apud Herrero Cecilia, 176) recae en el cuerpo del texto, caracterizado por la presencia de dos cláusulas: de proposición y de solicitud. Ejemplo:

OFREZCO: Apto. Luyanó, sala-comedor, $1 / 4$ grande c/ closet, baño amplio, cocina, patio, vista calle, gas calle, agua, moderno, buenas condiciones. Rosa Enríquez No 426 e/ Municipio y Rodríguez, apto. 20 Eloísa.

NECESITO: Ampliarme cualquier lugar.

Tanto la cláusula de proposición como la de solicitud se encabezan con el verbo en tipo mayor que el resto del mensaje y siempre conjugado en la primera persona del singular del presente de indicativo, seguido de dos puntos (OFREZCO: NECESITO:), de donde se advierte que la revista reproduce el modo de la concepcionalidad de la cercanía y la individualidad del proponente; esto es, el enunciador intratextual y el extratextual se hacen coincidir, como si no hubiera elaboración.

En la cláusula de proposición aparece -en el orden que a continuación se reseñala descripción abreviada de la vivienda:

\footnotetext{
${ }^{4}$ Véase para este tipo de consideraciones Núñez y Del Teso (1996: 179).
} 
Primero: si se trataba de una casa, apartamento o habitación. La jerarquía establecida en los implícitos culturales se colige del orden de colocación. Para el imaginario de la comunidad receptora, en consecuencia, el inmueble de mayor entidad es la casa independiente, por antonomasia casa, y el de menor una habitación, que forma parte, generalmente, de un solar o casa de vecindad ${ }^{5}$ ).

Segundo: municipio o reparto en que estaba ubicada la vivienda ${ }^{6}$.

Tercero: piezas de la vivienda (sala, comedor, baño, etc.). Las habitaciones para dormir, llamadas normalmente en Cuba cuartos, pasaron a representarse abreviada y simbólicamente del siguiente modo: 1/4, 2/4, 3/4, 4/4, 5/4...). Este recurso, y otros como el empleo del signo de multiplicación (X 'por') dan muestras del carácter desenfadado e irreverente que estos textos pretendían o simulaban, vinculado con la novedad que se espera del anuncio, por un lado, y de otro con la ruptura de cánones propia de la comunicación oral ${ }^{7}$. En general, se emplean diferentes recursos de abreviación de los transpositores, o su eliminación, y también la de los morfemas libres: gas (de la) calle ${ }^{8}$. La expresión y demás comodidades, luego abreviada d/com., se usaba al final de la enumeración más o menos detallada de cualidades apropiadas de la vivienda ofrecida, para dejar abierta a la imaginación del posible destinatario otras ofertas convenientes que no se hacían explícitas, pero que serían presupuestas para toda vivienda que se pretendiera permutar.

Esta cláusula es la más libre dentro de la estructura, y en algunos casos es muy evidente la acumulación de «palabras ronroneo» como amplio, bueno, céntrico, magnífico, independiente, moderno, así como de otro lado el escamoteo de cierta condición que se consideraba no sería del agrado de los interlocutores: semiinterior ${ }^{9}$, ler. piso (18 escalones). El volumen de texto y estos recursos ameliorativos, así como la imagen de modernidad y rapidez que puede obtenerse de las abreviaciones y sintaxis telegráfica son una «estrategia de seducción», basada en el «contrato de fantasía» que el anunciante quiere establecer con su interlocutor, y para lo cual busca una presentación atractiva de la vivienda, que la convierta en deseable, y logre el efecto reactivo.

Tal estrategia implica el conocimiento de valores y estereotipos culturalmente establecidos para la comunidad objeto de la «publicidad» como son la elegancia, la belleza, la comodidad, la seguridad. En esta etapa el interlocutor al que evoca el texto de

5 Por lo cual la palabra «habitación» podría ser en este caso un eufemismo.

6 En la medida en que pasa el tiempo esta información se da de modo más flexible, o se omite.

7 Algunos anuncios destacaban las ventajas de la vivienda, como en: baño amplio, buen estado, cocina grande c/ estantes y closet; de los servicios públicos que recibía: gas calle, luz siempre; del entorno en que estaba ubicada: lugar céntrico, magníficas comunicaciones de transporte.

${ }^{8}$ En La Habana el nombre de gas de la calle se aplica al que se recibe por tuberías instaladas de manera permanente en las casas, y que se diferencia del llamado gas de balón, licuado, que se transporta por bombonas.

9 Interior se dice del apartamento o habitación que no da a la puerta principal del edificio o construcción en que se halla enclavado.

NORMAS. REVISTA DE ESTUdIOS LINGÜÍSTICOS HISPÁNICOS, NÚMERO 1 (AÑO 2011):

http//www.uv.es/normas

(ISSN 2174-7245) 
modo predominante es un no conocedor (+ afectivo), y por ello se hace característica la frase suspensiva «y demás comodidades», que deja, precisamente, un espacio a la ambigüedad de la oferta y que, por tanto, puede funcionar en el objetivo de seducción.

Cuarto: dirección de la vivienda y/o teléfono del proponente, con el nombre. Al igual que en el cartel callejero, el nombre es generalmente femenino y se consigna sin apellido; si este aparece, el proponente es un hombre ${ }^{10}$.

La cláusula de solicitud después del verbo introductorio no contiene formas fijas $\mathrm{y}$, en general, es más breve que la de proposición: Ampliarme cualquier lugar, Apto. similar 1ro. o 2do. piso, Apto. 1/4; analizo variantes, Apto. 2/4, demás comodidades. Eventualmente se anotan las cualidades no deseadas, en estructuras donde el adverbio de negación se antepone a sustantivos: no micro ${ }^{11}$, no Centro Habana o Habana Vieja. Este tipo de añadidos separan a los anuncios de permutas de los convencionales, al significar un rechazo de ciertos públicos y la desactualización de la intención persuasiva. Actuarían, en ese sentido, como «antianuncios».

La fijación de las formas hace que, andando el tiempo, puedan perderse las bases y cargarse los adyacentes de esos significados, aunque la elipsis sea contextual: NECESITO: (casa, apartamento, ...) similar con... De nuevo aquí el proceso de contextualización propio de la lengua escrita no se presenta de modo total.

Fue característica la presencia en estos anuncios de enunciados eufemísticos relativos a un acuerdo de dinero, que se formulaban de manera encubierta como: Oigo (o escucho) proposiciones.

Desde el punto de vista léxico, merece destacar que solo son evidentes pocos

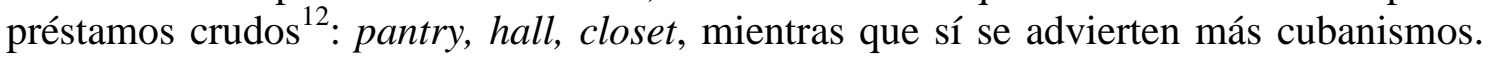
Se trata de voces de origen indoamericano, sometidas a procesos de reestructuración sémica, como barbacoa, muy reiterada, en la acepción que se consigna como cubanismo en el DA, o patrimoniales igualmente resemantizadas como casa, habitación, cuarto, cuadra, gas de la calle, luz y alguna creación neológica como micro(brigada).

Esta última característica se contradice con el deber ser del anuncio publicitario en que se supone (González Borges, 2006) debe subordinarse el léxico local a uno más universal, pero se compadece perfectamente con el propósito de quien permuta.

\footnotetext{
${ }^{10}$ Aunque este asunto no se relaciona directamente con nuestro tema, aquí se ve cómo en el habla cubana el apellido solo se emplea como forma de tratamiento apelativa o referencial para los hombres esencialmente.

${ }^{11}$ Micro, abreviación de microbrigada, resultado obtenido por elipsis de la expresión (edificio de) microbrigada, sistema de construcción de edificios multifamiliares económicos en serie, con el trabajo de quienes van a vivir en ellos.

${ }^{12}$ En las demás fuentes analizadas la nómina es igualmente reducida, y prácticamente nula en la emisora de televisión provincial.
}

NORMAS. REVISTA DE ESTUDIOS LINGÜÍSTICOS HISPÁNICOS, NÚMERO 1 (AÑO 2011): http://www.uv.es/normas

(ISSN 2174-7245) 
Así, la intención comunicativa se fija en los anuncios de Opina, y la escenografía textual comienza a estabilizarse. Esta formalización influirá tanto en el curso posterior del anuncio callejero como en su articulación en otros soportes.

Aunque ciertos rasgos establecidos como característicos de la sintaxis publicitaria (González Pastor, 1977) se cumplen en los materiales analizados, tales como la brevedad o la escasez de signos de puntuación, o de relatores, no predominan las estructuras nominales, pues los verbos introductorios actúan al mismo tiempo como organizadores del texto y como declarativos de las intenciones del enunciador.

\section{La estructura de la base de datos de la Dirección PRovincial de la Vivienda EN LA CIUDAD DE LA HABANA}

Movido por la necesidad y condicionado por lo que había fijado Opina, el anuncio de permutas pasó a otros medios en la radio, la televisión e Internet, y se formalizó aún más a través de una planilla ${ }^{13}$ elaborada por la Dirección Provincial de la Vivienda en la ciudad de La Habana (DPV $\left.{ }^{14}\right)$.

De este modo, el solicitante, al ir a colocar sus datos en la base, recibía una primera entrega de ofertas de acuerdo con sus necesidades y posibilidades, con la siguiente estructura. Ejemplo:

Cláusula de entrada: Permutas 1 x 1

Cláusula de ofrecimiento: OFR.: Apto. Bajos 3 Hab. Baño Sal-Com Coc Telf Gas

Calle puerta calle, pasillo lateral Mun. Plaza

Cláusula de solicitud: NEC.: Apto. 3 Hab Telf Gas

Cláusula de cierre: INF: Tel.\#\#\#\#\#\#\#\#. Calle \#\#. No. \#\# E/ B y C. Vedado.

Nélida. Desp. 5 pm.

Debe tomarse en cuenta que este no es un documento que se publica en un medio, sino que es una salida de máquina para uso personal. Sin embargo, se advierte que, al mismo tiempo que se puede reconocer la estructura del cuerpo fijada antes: cláusula de entrada a la que se ha añadido el sustantivo permutas, cláusula de proposición y cláusula de solicitud, se focaliza la información de contacto en una cláusula independiente, que se coloca al final del anuncio y que llamaremos, por tanto, cláusula de cierre $^{15}$.

${ }^{13}$ Formulario.

${ }^{14}$ La DPV constituyó una base de datos electrónica, a partir de que los solicitantes rellenaran los campos que se muestran en el anexo 1.

${ }^{15}$ En los anuncios anteriores, si estaban fijados en la propia casa objeto de permuta, esta información era superflua. De lo contrario, los datos se colocaban en la cláusula de proposición y podían ser la dirección completa del inmueble que se permutaba o de otro donde informarse, o un teléfono.

NORMAS. REVISTA DE ESTUDIOS LINGÜÍSTICOS HISPÁNICOS, NÚMERO 1 (AÑO 2011):

http//www.uv.es/normas

(ISSN 2174-7245) 
El volumen de texto queda reducido al mínimo, aunque la cláusula de proposición sigue siendo la más extensa.

Esta estructura se aparta de los cánones de los anuncios clasificados, pues se reducen o desaparecen los adjetivos valorativos de las piezas del inmueble $\mathrm{u}$ otras ventajas que antes se ponderaban.

El acto persuasivo se oscurece aún más, para presentarse como una mera información, en que el propio significado léxico de los elementos fundamentales (tipo de inmueble, número de cuartos de dormir, piezas restantes, servicios, municipio) y el de las piezas léxicas adicionales: puerta calle, balcones, patio, 2 ascensores será lo que actúe para el convencimiento. En otras palabras, se explota el universo de saberes de los miembros de la comunidad para organizar el texto ${ }^{16}$.

Sin embargo, en estos documentos se nos ofrecen datos sobre la imagen del enunciatario, en cuanto a expectativas de comodidad, amplitud y estatus que van más allá del mero reacomodo de la primera etapa.

\section{EL ANUNCIO DE PERMUTAS EN LA RADIO}

\subsection{La noticia radiada}

Las emisoras de radio COCO y Radio Metropolitana fueron pioneras en ofrecer a la población un servicio de anuncios de permutas. Al tratarse de una oralidad elaborada, su estructura se pretende más flexible que la de la escrituralidad (no marcación clara de cada cláusula, variedad de verbos introductorios -ofrece, permuta, tiene, cuenta con, vive, necesita, quiere, busca, aspira a alcanzar-, etc.), y se caracteriza por el tempo acelerado y la presencia de algunos transpositores y conectores. Frente a la sintaxis cortada de Opina, aquí se muestra una organización «narrativizada» más fluida. Ejemplos:

Cecilia permuta apartamento de tres cuartos en cuarto piso zona 2 Alamar. Necesita apartamento de al menos dos cuartos con garaje o posibilidades de hacerlo en zona 4 de Alamar. Puede marcar el (\#\#\#\#\#\#\#).

María tiene un precioso apartamento de dos cuartos, en óptimas condiciones y estado constructivo. Quiere ir a vivir a Alamar. Marque el (\#\#\#\#\#\#\#\#\#).

La cláusula de cierre, de presencia estable como es lógico, es polimórfica, aunque al parecer esta variabilidad se relaciona con el locutor que la elabora sobre la marcha, de

\footnotetext{
${ }^{16}$ Sobre la contraposición información / persuasión véase, por ejemplo, Costa Solá-Segalés.
} 
modo que algunas son más conminativas que otras. Mientras el resto del texto se dice rápidamente, el número telefónico se repite por dos veces. Ejemplos:

Para más información pueden llamar al \#\#\#\#\#\#\#.

Marque el \#\#\#\#\#\#.

Márquele ${ }^{17}$ a Vivian por el número \#\#\#\#\#\#.

Márquele por el número \#\#\#\#\#\#, o llámela ahora mismo a su trabajo: \#\#\#\#\#\#.

\#\#\#\#\#\# Todo el día esperará por usted.

Puede escucharse estructuras marginales de toma de turno: «Hay otro caso por aquí», y otras que destacan por la presencia de nexos: «porque en realidad lo que ella necesita ahora...»; «por eso está dispuesto a dejar...»; que alejan estos anuncios del cánon formal.

Asimismo, se advierte cierto desplazamiento del interés hacia la cláusula de solicitud, que aumenta su volumen, y oscurece la intención de seducir o persuadir, en la tesitura de lo peticionario. En este sentido, algunos textos pretenden despertar sentimientos hacia las necesidades del enunciador extratextual -rasgo impensable para un anuncio publicitario, aunque propio de otros productos radiales-. En contraposición, hay otros casos en que la cláusula de solicitud se reduce tanto que pierde la mención específica al tipo de inmueble, sustituida por un indefinido: Busca algo en Regla. La función de esta forma de presentación es construir una imagen del enunciador extratextual como sumamente moderado en sus expectativas y, por tanto, animar al enunciatario a comunicarse con aquel.

De otro lado, se documentan algunas lexías expresivas (precioso), tal como en la prensa plana, incluso con derivativos afectivos (cerquitica), y la fórmula eufemística «otras comodidades» con variantes.

Por último, adquiere peso el enunciatario, que puede presentarse como un conocedor, en la medida en que el acto persuasivo pueda ir dispuesto como una información dada en las piezas léxicas claves para moverlo a través de su racionalidad, como en la reiterada mención a placa libre ${ }^{18}$.

En fin, la forma última de las noticias radiadas está condicionada al menos por dos variables: la redacción de los datos de entrada por el enunciador real ${ }^{19}$, y la impronta de la persona que realiza la locución; y en cuanto a la intención y los participantes, constituye una estructura enfocada bien hacia el enunciador extratextual (necesidad $\rightarrow$

${ }^{17}$ El intento de expresividad, para despertar el interés, puede llevar a este locutor a usar normas ajenas a las del país, como la reflejada en este ejemplo.

${ }^{18}$ De la información contenida en el conjunto estable placa libre el enunciatario infiere nuevas opciones constructivas.

${ }^{19}$ De donde se justifica el siguiente epígrafe.

NORMAS. REVISTA DE ESTUDIOS LINGÜÍSTICOS HISPÁNICOS, NÚMERO 1 (AÑO 2011):

http//www.uv.es/normas

(ISSN 2174-7245) 
pedir) (mínima necesidad $\rightarrow$ persuadir), o hacia el enunciatario desde lo inconsciente (valor $\rightarrow$ seducir) o desde lo racional (valor $\rightarrow$ persuadir).

\subsection{Las notas escritas por proponentes para ser radiadas}

Sin embargo, son de mayor valor las notas escritas que dejan los interesados en la recepción de las emisoras para que sean transmitidas, y que pueden considerarse a medio camino entre la fijeza de la estructura de la DPV y las orales de los inicios.

En estas, muchas de ellas manuscritas, aunque se diferencian claramente las dos partes del cuerpo del texto, se perciben variaciones: no siempre se conjuga en la primera persona, ni tampoco el verbo de la primera cláusula es siempre ofrezco, sino que predomina permuto, en altas o en bajas, seguido de dos puntos o no. En ocasiones no hay verbo introductorio: Apartamento 2 cuartos, y en otras lo antecede una especie de encabezamiento: Permuto casa de Camaguey (sic) para ciudad de La Habana, Permuto $2 \times 1$, que incluye lo que el proponente considera esencial, y que funciona a modo de cláusula introductoria. Todo ello nos deja ver la influencia del medio en la regularización de las estructuras ${ }^{20}$ y los niveles de contextualización.

Estos textos pueden presentar mayor regodeo en la sintaxis, con presencia de elementos conectores y transpositores y otros verbos introductorios, deícticos, etc. y en ellos pueden aparecer relaciones de subordinación, ausentes en otros. Ejemplo:

Lourdes permuta una casa en el municipio Centro Habana. Tiene sala-hall, comedor, 4 cuartos, cocina, baño, patio con pozo aéreo, encima de la cocina tiene una barbacoa como cuarto de desahogo y terraza.

NECESITO: 2 apartamentos que tengan un cuarto cada uno en los municipios Centro Habana o Plaza.

Sin embargo, se advierte en el ejemplo la influencia de la forma escrita, que hace pasar sin transición de la tercera persona (Lourdes permuta) que correspondería a lo que se supone leerá el locutor, a la primera, sin desplazamiento (NECESITO). Este ejemplo, en su propia irregularidad, muestra la conciencia del enunciador real sobre las convenciones que se elaboran para cada medio.

También pueden encontrarse procedimientos de acumulación e intensificaciones expresivas, no canónicas para la radio:

\section{PERMUTO:}

Apartamento de 1 habitación con closet, en Centro Habana, cayo (sic) Hueso, a dos cuadras de 23 (Zona de la Rampa)

${ }^{20}$ Nótese la diferencia entre el texto oral individual, la oralidad elaborada, el escrito privado, y el público.

NoRMAS. REVISTA DE ESTUdIOS LINGÜÍSTICOS HISPÁNICOS, NÚMERO 1 (AÑO 2011):

http://www.uv.es/normas

(ISSN 2174-7245) 
Es en 3er. piso del año 1958, en buen estado, tiene 54 escalones. El baño, la cocina y el patio acabados de arreglar, azulejeados, todas las piezas nuevas, con lavadero, vertedero, además área para tender donde da el sol.

Es muy fresco y claro, vista al mar por la habitación, y lateral a la calle por el patio, es semiinterior. Tiene además sala-comedor, teléfono y gas de la calle.

NECESITO: Apartamento o casa de 1 habitación y además comodidades; solo hasta 3er. piso si no tiene elevador, en el Vedado exclusivamente.

Asumo reparación de cocina y baño, no de techos.

Son características de estas minutas para preparar los anuncios de permutas los incisos, del tipo: aunque pierda 1 cuarto, posibilidad de ampliación (puntal alto), donde se puede guardar un Fiat Polsky.

Al igual que la sintaxis, el léxico puede evidenciar su filiación con la oralidad, como en el siguiente ejemplo donde se advierte algún coloquialismo y el volumen de texto con rectificaciones y ampliaciones:

Permuto una casa accesoria de mampostería y placa con patio de tierra, cochiquera amplia y en buen estado, 2 cuartos, cocina, portal, baño, 2 cuartos de desahogo, 2 terrazas, todo el patio tapiado con muros de hasta $3 \mathrm{~m}$ de alto, cisterna (aunque no falta el agua), con posibilidades de ampliación.

- La vivienda está ubicada en la Salud municipio Quivicán.

- Aclaro que la vivienda tiene frente a la calle.

Necesito algo para Santa Fe, Víbora o cualquier municipio de Ciudad Habana.

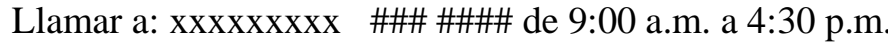

En cuanto a conjuntos léxicos estables abunda la expresión placa libre o techo libre, escasa en Opina, y también posibilidades de ampliación, así como algún préstamo infrecuente en la etapa anterior como carporch.

Sin embargo, otros llevan el texto hasta su mínima expresión, de tendencia telegráfica, en que el condicionamiento cultural del anuncio está dado en los aspectos léxico-semánticos (por ejemplo, los vocablos nucleares permuto, micro, Playa, Vedado, cuarto piso en el ejemplo siguiente) y en las formas de abreviación (11/2):

Permuto apartamento (de) micro en Playa (de) dos cuartos y medio, cuarto piso por apartamento (en) Vedado (de) $1 \frac{1}{1 / 2}$ cuartos no importa micro. Informe Teléfono \#\#\#\#\#\# Nombre de pila de mujer.

\section{EL ANUNCIO DE PERMUTA EN LA TELEVISIÓN LOCAL}

En cuanto a los textos para ser leídos por la televisión, contamos con una muestra del Canal Habana, cuya estructura básica presenta cláusula de ofrecimiento, de solicitud $\mathrm{y}$ de cierre, pero, al igual que en las noticias radiadas, diferencia el enunciador intratextual del extratextual: el sujeto tácito en tercera persona del plural sin antecedente

NoRMAS. REVISTA DE ESTUdIOS LINGÜÍSTICOS HISPÁNICOS, NÚMERO 1 (AÑO 2011):

http//www.uv.es/normas

(ISSN 2174-7245) 
o referente permite interpretar ese argumento inespecífico como encubierto (NGLE, 2009: 2002 y ss. y 2553 y ss.), y en cierto sentido que el canal televisivo no se hace responsable por la veracidad de los datos que se dan, ni de las gestiones para el intercambio directo. Los verbos introductorios son fijos (ofrecen y necesitan); a continuación aparecen unas pocas características de la vivienda que se propone o se requiere, y los cambios se explican por la intención de que no resulte tan monótona la repetición de los mismos sustantivos o estructuras. Ejemplo:

1-OFRECEN: apartamento con 1 habitación en Alta Habana, Boyeros. NECESITAN: similar en el Cerro, Plaza, Centro Habana, La Habana Vieja ${ }^{21}$.

2-OFRECEN: apartamento, biplanta, con 2 habitaciones y balcón en Consolación del Sur, Pinar del Río. NECESITAN: apartamento con 1 habitación en Ciudad de La Habana.

3-OFRECEN: UNA POR DOS: casa, biplanta, con cubierta libre, 3 habitaciones y patio en la Lisa. NECESITAN: vivienda con 2 habitaciones, hasta un 1er. piso, y apartamento con 1 habitación.

La cláusula de cierre se introduce con el verbo comunicar (si es por teléfono, mayoritario) o contactar (si se trata de una dirección postal) en infinitivo, con lo cual se mantiene la indeterminación no solo para el proponente sino también para la audiencia y se indica el nombre de contacto (de nuevo preferentemente mujeres), y un teléfono o una dirección. A veces se incluye, además, un adjunto para la restricción temporal de las llamadas (de inicio o de término): Comunicar con Niurka al \#\#\#\#\#\#, después de las 8:30 de la noche.

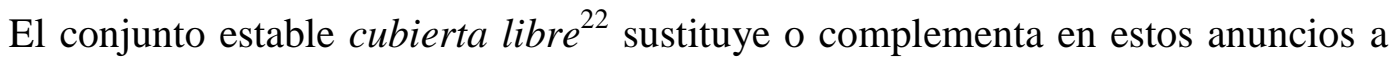
placa libre, en el reclamo mantenido de que el inmueble tenga el techo disponible para una nueva construcción. La alternancia de formas como estas se explica por la necesidad de buscar continuamente las más cultas (y por tanto más «apropiadas» para el medio televisivo), de modo que cuando una se extiende en el uso, aparece enseguida otra. Así se generan series sinonímicas, matizadas en virtud de la estimación social de las piezas léxicas que las integran.

En algunos textos televisivos son frecuentes los sintagmas preposicionales, referidos especialmente a los materiales de que está hecho el techo o la casa: de canelón, de prefabricado, de mampostería y madera. Se incluyen, además, las voces

${ }^{21}$ Nótese que la relación de disyunción o equivalencia se presenta de modo asindético.

${ }^{22}$ En general el vocablo cubierta sustituye al de uso oral techo en estos anuncios. Como nadie habla de este modo, el uso de formas léxicas exclusivas de los anuncios de permuta se convierte prácticamente en una jerga o tecnolecto.

NORMAS. REVISTA DE ESTUDIOS LINGÜÍSTICOS HISPÁNICOS, NÚMERO 1 (AÑO 2011): http://www.uv.es/normas 
biplanta, triplanta, no recogidas en el DRAE, pero sí en el DA con marca de cubanismo.

Se observa que mientras en los anuncios de todos los momentos y formatos la descripción mínima del inmueble incluye el número de habitaciones, en los de la televisión local aparecen, además, los elementos del campo léxico relativo a los espacios adicionales de la vivienda (cubierta libre, balcón, patio, garaje, portal, jardín).

A diferencia de los textos radiales, no se emplean aquí estructuras que indiquen el tránsito de un anuncio a otro, probablemente porque la visualidad del medio las hace innecesarias.

Otra característica definidora de estos anuncios es que tienen menor volumen de texto y en ellos resalta más la función informativa que la persuasiva, de modo que escasean los adjetivos valorativos y los derivativos apreciativos. En consecuencia, estos textos serían más cercanos a los de la base de datos de la DPV.

\section{EL ANUNCIO DE PERMUTA EN INTERNET}

Finalmente, algunos sitios en Internet, con las posibilidades que este soporte ofrece, se dedican a anuncios de permutas.

En <sepermuta.com>, aprovechando los recursos del medio, la estructura se inicia con la fecha de publicación del anuncio, un código (consecutivo) y la clase de permuta $(1 \times 2,2 x 1,1 \times 1$ cláusula de entrada en otros medios), para situar a continuación un hipervínculo (Más detalles), abierto el cual se muestra prácticamente la misma organización del cuerpo del texto reseñada para Opina, con los mismos verbos (cláusulas de ofrecimiento y solicitud). Se indica en el «ofrezco», en el siguiente orden, el tipo de inmueble, el piso en que está situado, el número de habitaciones, y el municipio o barrio. El «necesito» puede tener esta misma forma básica, pero precisa si se quiere algún barrio determinado dentro de los municipios solicitados o se acepta cualquiera $^{23}$ :

Pub: 20-Jul-2008 código 22406 Tipo 1x1 Más detalles...

OFREZCO apto., 3er piso, 2 hab en Ciudad Habana, Plaza de la Revolución, Nuevo Vedado.

NECESITO casa, en bajos, mínimo 3 hab, en Ciudad Habana: Plaza de la Revolución (cualq. Barrio).

OFREZCO apto., 6to piso, 3 hab en Ciudad Habana, Plaza de la Revolución, Nuevo Vedado.

\footnotetext{
${ }^{23}$ Este formato es la salida de una base de datos, cuya entrada es el formulario que aparece en el anexo 2, que el proponente debe rellenar. Se puede advertir que el principio ordenador de la entrada son las necesidades, y el de la salida las propuestas.
}

NORMAS. REVISTA DE ESTUDIOS LINGÜÍSTICOS HISPÁNICOS, NÚMERO 1 (AÑO 2011):

http//www.uv.es/normas

(ISSN 2174-7245) 
NECESITO casa o apto., mínimo 2 hab, en Ciudad Habana: Centro Habana (cualq. barrio) Cerro (cualq. barrio) Playa (cualq. barrio) Plaza de la Revolución (cualq. barrio).

NECESITO casa o apto. o prop. horiz., mínimo 1 hab, en Ciudad Habana: 10 de Octubre (cualq. barrio) Arroyo Naranjo (cualq. barrio) Boyeros (cualq. barrio) Centro Habana (cualq. barrio) Cerro (cualq. barrio) Habana del Este (cualq. barrio) Habana Vieja (cualq. barrio) Marianao (cualq. barrio) Playa (cualq. barrio) Plaza de la Revolución (cualq. barrio).

Como se puede apreciar, el anuncio digital procede a una regularización del volumen de las cláusulas de proposición y solicitud. Se emplean algunas abreviaturas transparentes, aunque inusuales para un medio público, cuya funcionalidad puede ser, además del ahorro de tiempo y espacio, destacar la convención cultural común y el entendimiento entre enunciador y destinatario.

En estos anuncios, además, en la cláusula de cierre suelen aparecer con más frecuencia datos de los proponentes: nombres y apellidos, correos electrónicos personales e institucionales, introducidos a continuación del vocablo informes o la expresión contactar a, que ya no remite al encuentro cara a cara, sino que se refiere a teléfono o correo. De esta manera, en principio, un anuncio que aparentemente devela más al enunciador, puede en realidad representar una intención de filtro que permita a este, e incluso al enunciatario, decidir si quiere pasar a otro nivel de aproximación o no.

Por su parte el sitio <permutasencuba.infosoc.cu> presenta datos semejantes en el encabezamiento: Código de inscripción: 7690_9698 (Fecha: 2009-10-22 / 1 x 1: Ofrece una y necesita una), así como la misma estructura bipartita del cuerpo del texto, pero con los verbos en tercera persona del singular (ofrece y solicita $^{24}$ ). La inespecificidad de la tercera persona y el registro más culto de solicitar refuerzan la distancia concepcional:

Ofrece: Casa. Estado constructivo: Bueno. Piso 1 - . Tipo de construcción: Mampostería (Viga y losa). Sala-Saleta. Cocina. 4 dormitorios. 1 baño. Agua de cisterna con motor. Gas de la calle. Teléfono - Puerta a la calle - Balcón Azotea libre - Hall - En : Centro Habana.

Solicita: Casa. Estado Constructivo: Bueno. 4 dormitorios. Mampostería (Placa). 2 baños. Teléfono. Puerta a la calle. En Cienfuegos/Cienfuegos.

Aquí se añade un dato ausente en todas las variantes anteriores: el estado constructivo, con una escala habilitada al efecto; y el recuento es más exhaustivo que en otros soportes: tipo de vivienda, piso, materiales, piezas, servicios, disponibilidad de la

${ }^{24}$ Este verbo es más culto y asociable con la distancia concepcional que el común «necesito, -a».

NoRMAS. REVISTA DE ESTUdIOS LINGÜÍSTICOS HISPÁNICOS, NÚMERO 1 (AÑO 2011):

http://www.uv.es/normas

(ISSN 2174-7245) 
azotea, ubicación en relación con la calle o el edificio, municipio, etc. Ello es lógico si se tiene en cuenta que la base de datos de la que se parte es mucho más amplia que las anteriores, como se colige de los campos que debe rellenar el proponente (anexo 3) y la función que cumple esta prolijidad es la de ofrecer una imagen de veracidad ante el posible permutante.

De otra parte, se observa la presencia de valoraciones realizadas por el enunciador, libremente o según escalas que le son fijadas por el sitio.

Las cláusulas finales de estos documentos se obtienen de completar los siguientes datos: Preguntar por: Dirección: Correo electrónico:, por lo que, al igual que en <sepermuta.com>, se suelen presentar los nombres con sus apellidos, teléfonos varios, direcciones postales completas y direcciones de correo electrónico personales y corporativas.

Es evidente, entonces, que la estructura de este tipo de textos, en el soporte escrito o multimedial, se ha ido perfeccionando hasta añadir un total de al menos 11 etiquetas (subcampos) a los datos, cuyo estudio más amplio puede iluminar el campo léxico de la casa $^{25}$ :

Tipo de inmueble: (en orden jerárquico de preferencia): casa independiente, casa, propiedad horizontal, apartamento, habitación ${ }^{26}$.

Antigüedad: según fecha de construcción (no se fija escala, la consideración queda a juicio del solicitante).

Tipo de permuta: (en orden de frecuencia y necesidad): $1 x 1,1 x 2,2 x 1 \ldots$ (la primera se explica, con verbo en primera persona del singular: ofrezco una y necesito una).

Estado constructivo: la escala creada por el sitio comprende: bueno, necesita reparación ligera, necesita reparación profunda. Alguno de ellos puede resultar eufemístico.

Piso: sótano, planta baja, primer piso, segundo piso..., pent house.

Tipo de construcción: alude a los materiales de paredes y techo: placa (mampostería y techo de hormigón), viga y losa (mampostería y techo montado con estos materiales), madera, techo ligero ${ }^{27}$...

Cantidad de dormitorios ${ }^{28}$ y cantidad de baños: en ningún caso se supone la posibilidad de que falten estas piezas.

${ }^{25}$ Estos datos podrían confrontarse con los que arroja el estudio de las respuestas al cuestionario onomasiológico correspondiente al grupo 4 del Proyecto Coordinad de investigación de las hablas cultas de Iberoamérica «Juan M. Lope Blanch».

${ }^{26}$ También llamada cuarto.

${ }^{27}$ Fibrocemento: sistema de techado elaborado industrialmente sobre la base de una masa de papel, cartón y telas, solidificado con cemento y a la que se da una estructura continua de crestas y valles.

${ }^{28}$ Se emplea esta palabra de un registro más formal en lugar de la habitual cuarto.

NORMAS. REVISTA DE ESTUDIOS LINGÜÍSTICOS HISPÁNICOS, NÚMERO 1 (AÑO 2011):

http//www.uv.es/normas

(ISSN 2174-7245) 
Otras habitaciones: sala, saleta, sala-comedor, cocina, cocina-comedor; aparece la opción «sin sala»y «sin cocina».

Servicios: agua (de la calle ${ }^{29}$, cisterna con motor, pozo), gas (de la calle, de balita $^{30}$, de balón), querosén ${ }^{31}$, electricidad u otro combustible ${ }^{32}$, teléfono, elevador.

Otras piezas o disponibilidades de la casa: garaje (cerrado, car-porch, colectivo o común), patio ( y patio de tierra), jardín, portal, terraza, balcón, hall. La existencia de una barbacoa ${ }^{33}$ o de medio cuarto $^{34}$, así como de las otras piezas mencionadas en este acápite y la disponibilidad de la azotea libre suelen ser interpretadas por los solicitantes como espacios de ampliación de las posibilidades, por lo cual actúan como ganchos para atraer su atención.

En los sitios web, como es habitual para este tipo de producto informático, el texto escrito va acompañado de imágenes donde el destinatario podría comprobar la veracidad de los datos que se le ofrecen. Esta condición, unida a la exhaustividad de la descripción de la vivienda, nos permiten colegir que el destinatario deseado, acaso más culto y reflexivo (+racional), se guiará por los datos y la información visual, y no por las valoraciones edulcoradas del proponente, de manera que el anuncio se orientará hacia esta estructura.

\section{CONCLUSIONES}

El anuncio de permutas, como se ha visto, puede considerarse un tipo del subgénero anuncio clasificado dentro del género publicitario. Comparte con este la claridad y brevedad, y, de modo general, la estructura más o menos fija, la restricción o eliminación de determinantes, conectores o transpositores. Sin embargo, no es tan importante aquí la creatividad ni el diseño tipográfico, por ello se acerca más al anuncio tradicional, basado en las ventajas de lo ofrecido per se -el objeto de permuta en este

${ }^{29}$ Se nombra de este modo al agua que entra por gravedad, directamente desde las tuberías de las redes públicas, sin necesidad de ser movida por un medio eléctrico o acumulada en una cisterna del inmueble.

${ }^{30}$ La diferencia entre balita (bombona) y balón está dada por las dimensiones del recipiente.

${ }^{31}$ Se prefiere al usual luz brillante. Querosén es el nombre genérico del dominio transaccional, al menos en La Habana.

32 Carbón o leña, por ejemplo.

${ }^{33}$ Aunque la barbacoa, por los materiales con que suele construirse o la forma en que ello se hace, puede ser causa de rechazo de un inmueble.

${ }^{34}$ Medio cuarto: habitación muy pequeña, pero en la que es posible colocar algún mueble para dormir.

NoRMAS. REVISTA DE ESTUdIOS LINGÜÍSTICOS HISPÁNICOS, NÚMERO 1 (AÑO 2011):

http://www.uv.es/normas

(ISSN 2174-7245) 
caso- que al moderno, centrado en las imágenes y la calidad estética, según Guerra (1999: 20).

En cuanto a su modalidad de enunciación es declarativa, pero su modalidad de enunciado es volitivo-apreciativa, pues su intención, como en todo anuncio, es seductiva o persuasiva, de mover al destinatario a realizar el trueque. Esto quiere decir que, con mayor o menor claridad según el medio, se trata de textos explícitamente representativo-informativos, pero implícitamente directivos.

El público al que va dirigido el anuncio, de primera mano, son mujeres, de donde se infiere el elemento cultural de que estas guían u organizan procesos sociales de mucha entidad. Su carácter subjetivo se advierte en el empleo de adjetivación valorativa y de la primera persona pronominal o verbal. El medio donde se difunde (contacto o cartel callejero, prensa, radio, televisión, web) influye en el cambio de la forma subjetiva (yo) a la objetiva (sujeto de tercera persona singular o plural).

La atención se logra con el uso de las altas, y los verbos introductorios de cada una de las partes, además de la cláusula de entrada que indica el tipo esencial de permuta, que puede hacer las veces de una especie de titular abierto. Para el análisis probablemente son fundamentales las constantes que se reiteran de un soporte a otro, por cuanto muestran lo que resulta esencial para el imaginario y el estereotipo cultural de proponentes y destinatarios.

En unos casos el interés se estimula, además, mediante el empleo de modificadores, derivación apreciativa y de formas eufemísticas que suavizan los aspectos negativos de lo que se ofrece. En otros, el peso de lo informativo en sí mismo es lo que moverá el juicio y la acción del destinatario

Se hace evidente, en el paso del anuncio oral callejero, al de prensa, radial, televisivo o web que aunque todos cumplen la misma función informativo-persuasiva, algunos se colocan en el inicio de un proceso que requerirá recursos complementarios de información, y otros gozan de una mayor independencia y elaboración -así lo testifica tanto su volumen de texto como la selección de voces de registros más formales-, y que todos buscan adecuarse en mayor o menor grado al medio en que se producen.

Lo oral resultó insuficiente para estas necesidades y fue preciso comenzar a desarrollar una tradición escritural que debe muchos de sus caracteres constantes al influjo de Opina. El cambio de lo oral a lo escrito supone la aparición de estructuras formularias (partes y cláusulas) legitimadas por la autoridad de las instituciones que las promueven, lo que demuestra el carácter modélico y modelador de estas.

Sin embargo, estas formas más elaboradas no han desplazado completamente ni los coloquios sabatinos de Prado, ni los anuncios minimalistas de las puertas de calle o las paradas de los ómnibus.

La tradición textual del anuncio de permuta, a cuyo nacimiento y primeros desarrollos hemos asistido, se erige en fuente para el estudio de la evolución diacrónica del español cubano, a partir de los elementos de cambio que pueden encontrarse en

NoRMAS. REVISTA DE ESTUdIOS LINGÜÍSTICOS HISPÁNICOS, NÚMERO 1 (AÑO 2011):

http//www.uv.es/normas

(ISSN 2174-7245) 
textos de diferentes momentos, pero dependientes unos de otros en cuanto a la maduración y fijación de una estructura que va condicionando cada etapa ${ }^{35}$.

La adición de semas específicos al vocablo permutar (restricción semántica), la intransitivación de este verbo, la creación de un derivado inverso sustantivo, las formas neológicas circunstanciales como permutero o estables (corredor de permutas), muestran la productividad de este subdominio, matizado por la presencia de cubanismos.

De esta muestra puede desprenderse el carácter histórico del tipo, correspondiente a una época de falta de disponibilidades habitacionales, sobre todo en la capital, y en que ha sido preciso aprovechar todos los recursos, como se observa en los conjuntos léxicos más o menos estables como puntal alto, construir en la azotea, cerrar el portal, dividir la casa.

En la muestra analizada, el paso desde la mención frecuente a la barbacoa, hacia el requerimiento de la placa o cubierta libre, y de ahí a la descripción del estado constructivo de la vivienda marca una transición que corresponde con la agudización de la carencia y el agotamiento de aquella primera solución. Estos datos nos hacen ver la función de la tradición discursiva como «eslabón entre historia lingüística externa e interna» (Koch en Kabatek, 2001: 99).

Por eso el alcance potencial de esta tradición, que ha ido fijando rápidamente una estructura más o menos estable. El problema, y el tipo textual anuncio de permuta que con él se crea, repercuten a otras esferas de la vida, como las del derecho y las artes (música, cinematografía ${ }^{36}$ ), y aparecen en la prensa ligados al costumbrismo (ver anexo $5)$.

El anuncio de permuta en Cuba es, pues, un producto comunicativo para el consumo cultural, cuya índole lingüística y sociopragmática mueve y es movida por los estímulos, estereotipos y valores socioculturales y experiencias afines a su productor y a su interpretante.

El mensaje esencial que se obtiene de este tipo textual no se refiere a las características del producto transaccional, sino a la voluntad suasoria, y al acto directivo incluido. Se trata de crear expectativas y suscitar actitudes, pero al hacerlo, se reproducen unas creencias y unos valores.

En las selecciones léxicas, sintácticas y estructurales no solo se muestra el imaginario social que de este dominio y otros colaterales tienen los hablantes, sino que

\footnotetext{
${ }^{35}$ Véase sobre la índole de estos procesos Kabatek (2001: 97 y ss.).

${ }^{36}$ Sirvan de ejemplo el filme Se permuta y la canción de los Van van donde reza: dime dónde quieres que te ponga la barbacoa. En el anexo 4 una décima de Chanito Isidrón. Nótese como se satiriza el empleo de las formas ponderativas que no se corresponden con la realidad.
} 
también se perpetúa. Estudiar esa relación nos permite dar el salto entre lo que dicen y lo que realmente quieren decir las palabras de los anuncios de permuta.

\section{REFERENCIAS BIBLIOGRÁFICAS}

Asociación de ACAdemias de la Lengua Española (2010): Diccionario de americanismos, Madrid, Santillana.

ASOCIACIÓN DE ACADEMIAS DE LA LENGUA ESPAÑOLA y RAE (2009): Nueva gramática de la lengua española, Madrid, Espasa Libros, S. L. U.

CASSANY, Daniel (2004): «La expresión escrita», en Sánchez, Jesús e Isabel Santos, eds., Vademécum para la formación de profesionales. Enseñar español como segunda lengua L2/LE, Madrid, Sociedad General Española de Librería, S. A., 917-942.

COSSERIU, Eugenio (1981): Introducción a la lingüística, Madrid, Gredos.

COSTA SOLÁ-SEGALÉS, Joan: «La pospublicidad hacia el siglo XXI». Referencia en línea: http://www.magnacomunicacion.com.ar/enlace4art16.htm (consultado el 5 de enero de 2011).

GonzÁlez Borges, María de los Ángeles: «El mensaje periodístico de las agencias de noticias: recursos lingüísticos vs objetividad». Referencia en línea: http://mesadetrabajo.blogia.com/2006/110606-el-mensaje-periodistico-de-las-agenciasde-noticias-recursos-linguisticos-vs.-ob.php (consultado el 5 de enero de 2011).

GonZÁlez, P. (1977): Introducción a la sintaxis, Arequipa, Perú, Colegio Nacional de Independencia Americana.

GuRREA, Álvaro (1999): Los anuncios por dentro, Bilbao, Universidad del País Vasco.

Herrero Cecilia, J. (2006): Teorías de pragmática, de lingüística textual y de análisis del discurso, Ediciones de la Universidad de Castilla-La Mancha.

KABATEK, Johannes (2001): «¿Cómo investigar las tradiciones discursivas medievales? El ejemplo de los textos jurídicos castellanos», en Daniel Jacob y Johannes Kabatek, Lengua medieval y tradiciones discursivas en la Península Ibérica, Frankfurt am Main/Madrid, Vervuert/Iberoamericana, 97-132.

NúÑEZ, Rafael y Enrique DEL TESO (1996): Semántica y pragmática del texto común. Producción y comentario de textos, Madrid, Cátedra.

OESTERREICHER, Wulf (2001): «Textos entre inmediatez y distancia comunicativas. El problema de lo hablado escrito en el Siglo de Oro», en Cano, Rafael, coord., Historia de la lengua española, Barcelona, Ariel, 729-769.

OESTERREICHER, Wulf (2004): «La recontextualización de los géneros medievales como tarea hermenéutica», en Jacob, Daniel y Johannes Kabatek, Lengua medieval y tradiciones discursivas en la Península Ibérica, Frankfurt am Main/Madrid, Vervuert/Iberoamericana, 199- 231. 
RAMÍREZ CARO, Jorge (2001): «El paraíso terrestre de la publicidad». Referencia en línea: http://www.tec.cr/sitios/Docencia/ciencias_lenguaje/revista_comunicacion/Voumen\%20 11N\%BA3\%202001/Articulos/jramirez.htm (consultado el 5 de enero de 2011). 
ANEXO 1

Modelo para el solicitante de permuta. Oficina Provincial de la Vivienda

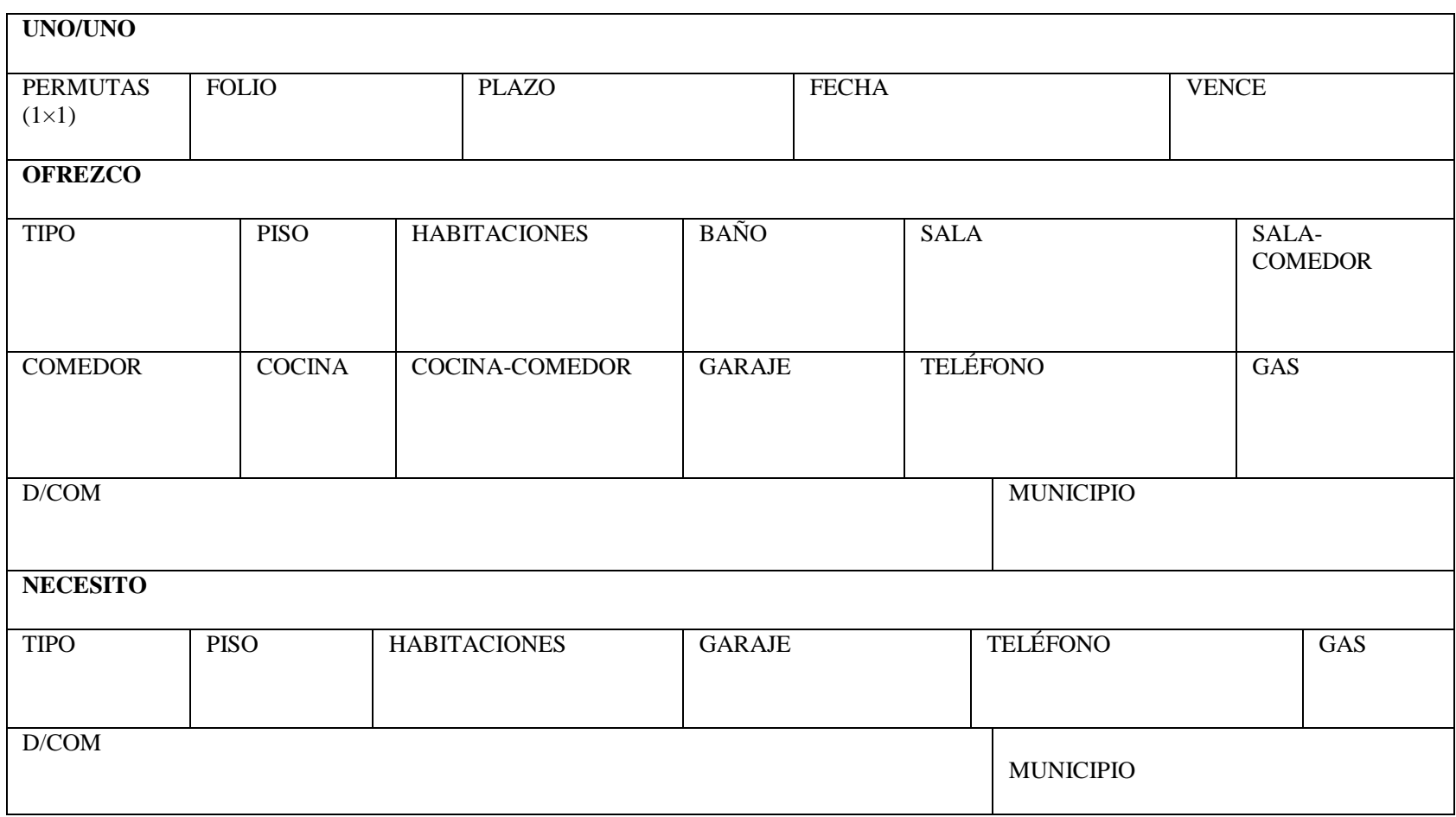

NORMAS. REVISTA DE ESTUDIOS LINGÜÍSTICOS HISPÁNICOS, NÚMERO 1 (AÑO 2011):

http//www.uv.es/normas 


\section{ANEXO 2}

\section{Modelo para el solicitante de permuta. Sepermuta.com} BUSCADOR DE PERMUTAS

\section{YO BUSCO}

- Cualquier tipo de permuta

$$
\begin{aligned}
& \square \quad \text { quien ofrece } 1 \text { vivienda y necesita } 1 \text { vivienda } \\
& \square \quad \text { quien ofrece } 1 \text { vivienda y necesita } 2 \text { viviendas } \\
& \text { quien ofrece } 1 \text { vivienda y necesita } 3 \text { viviendas } \\
& \text { quien ofrece } 2 \text { viviendas y necesita } 1 \text { vivienda } \\
& \text { quien ofrece } 3 \text { viviendas y necesita } 1 \text { vivienda } \\
& \text { quien ofrece } 2 \text { viviendas y necesita } 2 \text { viviendas }
\end{aligned}
$$
- Cualquier municipio_ $\square$ Provincia - $\square$ Municipio
- Mínimo de cuartos_ (Desde $1,1 \frac{1}{2}$ hasta $101 / 2$ )
- Máximo de cuartos_ (Desde $1,1 \frac{1}{1 / 2}$ hasta 10 1/2)

\section{YO TENGO}

- Cualquier municipio_

- Cantidad de cuartos_ $\quad \square$ (Desde 1 hasta 10 1/2) 
ANEXO 3

Modelo para el solicitante de permuta. Permutasencuba.infosoc.cu

FORMULARIO DE INSCRIPCIÓN EN LA BOLSA DE PERMUTAS

Nombre y apellidos:

Provincia:

Municipio:

Correo electrónico:

Nombre de usuario:

Contraseña:

BOLSA DE PERMUTAS

Tipo de permuta que busca: $\quad \square \quad \square \quad 1 \times 1$ (Ofrezco una y necesito una)

$$
\begin{aligned}
& 1 \times 2 \\
& 1 \times 3 \\
& 2 \times 1 \\
& 3 \times 1
\end{aligned}
$$

Antigüedad:

NECESITO (Primera opción. El número de opciones varía según el tipo de permuta que sea)

1- Tipo de vivienda:

_Casa __Casa independiente __ Apartamento ___Propiedad horizontal

_ Cuarto o habitación

2- Estado constructivo: $\quad \square \quad$ Bueno

Necesita reparación ligera

Necesita reparación profunda

3- Ubicación de la vivienda: $\quad \square$ Planta baja

Biplanta

NoRMAS. REVISTA DE ESTUdIOS LINGÜÍSTICOS HISPÁNICOS, NÚMERO 1 (AÑO 2011):

http//www.uv.es/normas 
Piso 1-20

Sótano

Pent House

4- Tipo de construcción: $\quad \square$ Mampostería (placa)

Mampostería (viga y losa)

Mampostería (techo ligero)

Madera

Mixto

Otro

5- Cantidad de dormitorios:

6- Distribución Sala/Comedor:

Sala

Sala-Saleta

Sala-comedor

Sin sala

7- Distribución Cocina: $\quad \square \quad$ Cocina

Cocina-comedor

Sin cocina

8- Cantidad de baños:

9- Agua: $\square$ De la calle

Cisterna con motor

Pozo

10- Garaje: $\square$ Garaje cerrado

Garaje común

Car-porsch

Posibilidad de garaje

NORMAS. REVISTA DE ESTUDIOS LINGÜÍSTICOS HISPÁNICOS, NÚMERO 1 (AÑO 2011): http://www.uv.es/normas 


\section{Sin garaje}

11- Combustible: $\quad \square \quad$ Gas de la calle

Gas de la balita

Gas de balón

Querosén

Electricidad

Otro combustible

12- Otras facilidades de la vivienda:

Teléfono

Elevador Barbacoa

13- Provincia: Puerta a la calle Azotea libre Jardín Patio Portal Patio de tierra Terraza Hall
Reparto:

OFREZCO (Primera opción. El número de opciones varía según el tipo de permuta que sea)

NOTA: Se piden los mismos datos que en la planilla donde se dan a conocer las características de la vivienda (o las viviendas) que se necesita.

1- Tipo de vivienda:

__ Casa __Casa independiente Apartamento Propiedad horizontal

Cuarto o habitación

2- Estado constructivo: $\quad \square \quad$ Bueno

Necesita reparación ligera

Necesita reparación profunda

3- Ubicación de la vivienda:

Planta baja

Biplanta

Piso 1-20

Sótano

Pent House

NORMAS. REVISTA DE ESTUDIOS LINGÜÍSTICOS HISPÁNICOS, NÚMERO 1 (AÑO 2011): http//www.uv.es/normas 
4- Tipo de construcción:

\author{
Mampostería (placa) \\ Mampostería (viga y losa) \\ Mampostería (techo ligero) \\ Madera \\ Mixto \\ Otro
}

5- Cantidad de dormitorios:

6- Distribución Sala/Comedor:

Sala

Sala-Saleta

Sala-comedor

Sin sala

7- Distribución Cocina:

Cocina

Cocina-comedor

Sin cocina

8- Cantidad de baños:

9- Agua: $\square$ De la calle

Cisterna con motor

Pozo

10-Garaje: $\square$ Garaje cerrado

Garaje común

Car-porsch

Posibilidad de garaje

Sin garaje

11- Combustible: $\square$ Gas de la calle

Gas de la balita

NORMAS. REVISTA DE ESTUDIOS LINGÜÍSTICOS HISPÁNICOS, NÚMERO 1 (AÑO 2011): http://www.uv.es/normas 
Gas de balón

Querosén

Electricidad

Otro combustible

12- Otras facilidades de la vivienda:

Teléfono Puerta a la calle Elevador Barbacoa Azotea libre Jardín Portal __ Balcón Terraza Elevador

13- Provincia:

Municipio: Patio Patio de tierra Hall

$\square$

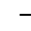

Reparto:

NORMAS. REVISTA DE ESTUDIOS LINGÜÍSTICOS HISPÁNICOS, NÚMERO 1 (AÑO 2011): http//www.uv.es/normas 


\section{ANEXO 4}

«Las permutas». En Recuento. Memorias de puño y letra de Chanito Isidrón (2009). Compiladoras Amor Benítez Hernández et al. Letras Cubanas.

Muchas gentes se dedican

a ver como cosas ciertas

el sin número de ofertas de permutas que publican.

En los anuncios explican las maravillas de un techo casi nuevo, muy bien hecho, y que su dueña lo ofrece porque es alto y padece ella de frío en el pecho. Otro ofrece permutar un chalet extraordinario porque eso está en El Calvario y él trabaja en Miramar. Otro se quiere mudar y está ofreciendo en El Cerro casa con verja de hierro, tres cuartos, sala, cocina, un baño de loza china y un cuartico para el perro. Otro casero anunciaba permuta para La Lisa y fuime hasta allá sin prisa a ver si me interesaba. La casa ofertada estaba del cementerio a un costado; yo, que en el Nuevo Vedado conozco los sitios serios y ya con los cementerios estoy familiarizado.

La casa es pequeña y chata, la cocina es sin fogón, con un baño de cajón y ducha de jarro y lata. Hay que echar una alpargata para ir de la casa al baño, sí que hay agua todo el año pero el que se cae se ahoga porque es acueducto a soga, rondana y cubo de estaño.

Me dije: «En Nuevo Vedado hace tiempo que vecino soy del cementerio chino y el Colón casi a un costado.

NORMAS. REVISTA DE ESTUDIOS LINGÜÍSTICOS HISPÁNICOS, NÚMERO 1 (AÑO 2011): http://www.uv.es/normas 
Aquí el de La Lisa, al lado de su palacio montuno, es cómodo y oportuno para mis huesos guardar pero yo no voy a dar dos cementerios por uno».

NORMAS. REVISTA DE ESTUDIOS LINGÜÍSTICOS HISPÁNICOS, NÚMERO 1 (AÑO 2011): http//www.uv.es/normas 